\title{
Sistem Pakar Mendiagnosa Penyakit Mata Katarak Dengan Metode Certainty Factor Berbasis Web
}

\author{
Rame R Girsang, Hasanul Fahmi
}

\begin{abstract}
Cataract is a major cause of vision and blindness in Indonesia. Currently, blindness in Indonesia causes cataracts to reach $30 \%$ when they are approved for 50 years, so this is something that deserves to be examined. With the advancement of advanced technology and saving experts in the field of eye needed an expert system is needed with the experts in the hope of helping the public to know more about cataracts before using cataracts. The method used to diagnose cataract is using the Certainty Factor method while the CF method shows the certainty of an uncertain fact and obtains a percentage rate of $95 \%$ according to the method of improvement. .
\end{abstract}

Keywords: cataract, expert system, Certainty Factor method

Abstrak-- Katarak merupakan penyebab utama gangguan penglihatan dan kebutaan di Indonesia. Saat ini kebutaan di Indonesia yang disebabkan mata katarak mencapai $30 \%$ pada umumnya berusia 50 tahun, sehingga hal ini menjadi hal yang layak untuk di teliti. Dengan kemajuan teknologi yang semakin canggih dan kurangnya tenaga ahli dibidang mata sehingga dibutuhkan sebuah sistem pakar yang mampu menyamai dengan ahli pakar dengan harapan dapat membantu masyarakat agar lebih awal mengetahui tentang penyakit mata katarak sebelum menderita penyakit mata katarak. Adapun metode yang digunakan untuk mendiagnosa penyakit katarak yaitu dengan menggunakan metode Certainty Factor dimana metode CF menunjukan nilai kepastian dari suatu fakta yang belum pasti dan memperoleh tingkat persentase dengan nilai $95 \%$ sehingga dengan adanya metode Certainty Factor dapat digunakan untuk mengetahui masing- masing pada setiap gejala.

Kata Kunci- katarak, sistem pakar, metode Certainty Factor

Manuscript received January 22, 2019. This work was supported inpart by Informatics Engineering Department of Maulana MalikIbrahim Islamic State University.

Rame R Girsang Author is with the Informatic Engineering Departement of STMIK Pelita Nusantara, Medan, Indonesia. email reginagirsang@yahoo.co.id)

Hasanul Fahmi Author is is the Informatic Engineering Departement of STMIK Pelita Nusantara, Medan, Indonesia. email h.fahmizuhri@gmail.com

\section{PENDAHULUAN}

Mata adalah panca indra yang berfungsi sebagai indra penglihat khususnya manusia bila mata terdapat iritasi dan tidak ditangani dengan cepat dapat menyebabkan kebutuaan[5]. Kasus kebutaan disebabkan oleh katarak dimana katarak adalah kondisi mata yang lensa mata menjadi keruh dan berawan[5]. dan katarak tidak terjadi pada usia dini saja tapi pada semua umur padahal katarak merupakan salah satu jenis kebutaan yang dapat dihindari dan dapat disembuhkan melalui operasi[2]. Secara umum jenis- jenis katarak terdiri dari 4 bagian yaitu : katarak sekunder, senilis, katarak komplikata, dan katarak traumatika, hal ini akan menjadi permasalahan jika tidak terdapat sebuah sistem pakar yang mampu mendiagnosa penyakit mata katarak maka supaya tidak terjadi permasalahan, dibangun sistem dengan basis pengetahuan yang dinamis sebagai alat bantu untuk mendiagnosa penyakit katarak.

Sistem pakar merupakan sebuah program komputer yang memiliki pengetahuan dari satu atau lebih pakar manusia dibidang tertentu yang menunjukkan kebijakan layaknya seorang pakar[1]. Kemampuan seorang pakar pada mengatasi permasalahan sistem ini dirancang untuk meniru kepakaran waktu menjawab pertayaan dan menyelesaikan suatu masalah baik dibidang peran penting. Seorang pakar dapat diganti oleh program komputer yang prinsip kerjanya untuk memberikan solusi seperti yang dilakukan oleh sistem pakar dan sistem ini tidak dapat bekerja sendiri tanpa menggunakan sebuah metode, maka digunakan metode Certainty Factor $(C F)$.

Metode Certainty Factor (CF) adalah sebuah metode yang membuktikan suatu fakta apakah pasti atau tidak yang berbentuk metric yang digunakan sistem pakar[7]. Oleh karena itu agar tidak terjadi kesalahan diagnosa maka dibangun sebuah sistem pakar dengan menggunakan metode Certainty Factor $(C F)$ [4].

Dari uraian diatas yang menjadi permasalahan adalah belum ada sistem untuk mendiagnosa penyakit mata katarak sehingga dengan adanya sistem pakar mendiagnosa penyakit mata katarak dengan metode Certainty Factor dapat memudahkan pasien untuk mengetahui penyakit mata katarak sejak dini. 


\section{LANDASAN TEORI}

\subsection{Pengertian sistem pakar}

Menurut T. Sutojoyo, Dkk Sistem pakar merupakan cabang dari Artificial Intelligence (AI) Yang cukup tua karena sistem ini mulai dikembangkan pada pertengahan 1960. Sistem pakar yang muncul pertama kali adalah General -purpose problem solver (GPS) yang dikembangkan oleh Newel dan simon[6]. pada penelitian yang dilakukan oleh B Jensen menyatakan bahwa Sistem pakar adalah program komputer yang mewakili dan menggunakan keterampilan dan pengetahuan satu atau lebih pakar manusia untuk memberikan kinerja berkualitas tinggi dalam domain tertentu. Sistem pakar menawarkan sejumlah manfaat jika dibandingkan dengan pakar manusia[3].

\subsection{Certainty Factor}

Salah satu teori yang dapat digunakan untuk menyelesaikan masalah ketidak pastian.Certainty Factor atau CF merupakan nilai untuk mengukur keyakinan pakar. CF diperkenalkan oleh Shortliffe Buchanan dalam pembuatan sistem pakar MYCIN untuk menunjukkan besarnya kepercayaan . CF menunjukkan ukuran kepastian terhadap suatu fakta atau aturan nilai tertinggi dalam $\mathrm{CF}$ adalah +1.0 (pasti benar atau Definity not) dan nilai terendah dalam CF adalah $-1,0$ (pasti salah atau Definity not) nilai positif mempersentasikan derajat keyakinan, sedangkan nilai negatif mempersentasikan derajat ketidakyakinan. Certainty Factor didefinisikan sebagai berikut:

$\mathrm{CF}(\mathrm{H}, \mathrm{E})=\mathrm{MB}(\mathrm{H}, \mathrm{E})-\mathrm{MD}(\mathrm{H}, \mathrm{E}) \ldots,,(1)$

Dimana:

$\mathrm{CF}(\mathrm{H}, \mathrm{E})=$ factor kepastian

$\mathrm{MB}(\mathrm{H}, \mathrm{E}) \quad=\quad$ ukuran kepercayaan / tingkat keyakinan terhadap hipotesis $\mathrm{H}$, ji ka diberikan / dipengaruhi evidence e (antara 0 dan 1)

$\mathrm{MD}(\mathrm{H}, \mathrm{E})=$ ukuran ketidak percayaan / tingkat ketidakyakinan terhadap hipotesis $\mathrm{H}$, jika diberikan / dipengaruhi evidence E (antara 0 dan 1)

Ada dua cara mendapatkan tingkat keyakinan dari sebuah rule yaitu:

a. Metode Net Belief yang diusulkan oleh E.H. Shortliffe dan B.G. Buchanan.

$\mathrm{CF}($ Rule $) \quad=\mathrm{MB}(\mathrm{H}, \mathrm{E})$.

$\mathrm{MB}(\mathrm{H}, \mathrm{E})=\left\{\begin{array}{cc}1 & \mathrm{P}(\mathrm{H})=1 \\ \frac{\max [\mathrm{P}(\mathrm{H} \mid \mathrm{E}), \mathrm{P}(\mathrm{H})]-\mathrm{P}(\mathrm{H})}{\operatorname{Max}[1,0]-\mathrm{P}(\mathrm{H})} \ldots .\end{array}\right.$
$\operatorname{MD}(\mathrm{H}, \mathrm{E})\left\{\begin{array}{cc}1 & \mathrm{P}(\mathrm{H})=0 \\ \min [\mathrm{P}(\mathrm{H} \mid \mathrm{E}), \mathrm{P}(\mathrm{H})]-\mathrm{P}(\mathrm{H}) \ldots \ldots\end{array}\right.$

Dimana:

$\mathrm{CF}($ Rule $)=$ factor kepastian

$\operatorname{MB}(\mathrm{H}, \mathrm{E})=$ measure of belief (ukuran kepercayaan terhadap hipotesis $\mathrm{H}$, jika diberikan evidence $\mathrm{E}$ (antara 0 dan 1$)$.

$\operatorname{MD}(\mathrm{H}, \mathrm{E})=$ measure of disbelief (ukuran ketidakpercayaan) terhadap evidence $\mathrm{E}$ (antara 0 dan 1).

$\mathrm{P}(\mathrm{H})=$ probalitas kebenaran hipotesis $\mathrm{H}$.
$\mathrm{P}(\mathrm{H} \mid \mathrm{E}) \quad=$ probalitas bahwa $\mathrm{H}$ benar karena fakta $\mathrm{E}$.

b. Dengan cara mewancarai seorang pakar.:

Tabel 1. nilai Certainty factor

\begin{tabular}{|l|l|}
\hline Uncertain term & $\mathrm{CF}$ \\
\hline Pasti tidak & -1.0 \\
\hline Hampir pasti tidak & -0.8 \\
\hline Kemungkinan besar tidak & -0.6 \\
\hline Mungkin tidak & -0.4 \\
\hline Tidak tahu & -0.2 to 0.2 \\
\hline Mungkin & 0.4 \\
\hline Kemungkinan besar & 0.6 \\
\hline Hampir pasti & 0.8 \\
\hline Pasti & 1.0 \\
\hline
\end{tabular}

Pada tabel 1 menjelaskan uncertain term dan nilai CF. Tabel 1 didapat dari interpretasi "term" dari pakar, yang sudah diubah menjadi nilai $\mathrm{CF}$ tertentu sesuai dengan tabel.

Jika belum ada nilai CF untuk setiap gejala yang menyebabkan penyakit, maka digunakan formula dasar yang digunakan untuk mendiagnosa penyakit.

1. Certainty factor untuk kaidah dengan premis / gejala tunggal ( single premis rules):

$\mathrm{CF}$ gejala $=\mathrm{CF}$ [user] * CF [pakar]....(5)

2. Apabila terdapat kaidah dengan kesimpulan yang serupa (similiary concluded rules) atau lebih dari satu gejala, maka CF selanjutnya dihitung dengan persamaan:

$\mathrm{CF}$ combine $=\mathrm{CF}$ old $+\mathrm{CF}_{\text {gejala }} *$ (1- $\mathrm{CF}_{\text {old }}(6)$

3. Sedangkan untuk menghitung persentase

Terhadap penyakit, digunakan persaman :CF

persentase $=\mathbf{C F}$ combine $* \mathbf{1 0 0}$

Masing- masing yang memiliki nilai $\mathrm{CF}$ diberikan pilihan interpretasi pada sesi penyakit.

- Tidak yakin $=0.0$

- $\quad$ (Ya)Kurang yakin= 0.1- 0.3

- $\quad$ (ya) sedikit yakin $=0.4-0.5$

- $\quad$ (ya) cukup yakin $=0.6-0.7$

- $\quad$ (ya) yakin $=0.8-0.9$

- $\quad$ (ya) sangat yakin $=1.0$

Yang memiliki gejala tunggal diawali dengan pemecahan kaidah (rule) yang memiliki kaidah majemuk.dan masing - masing rule baru dihitung $\mathrm{CF}$ nya menggunakan persamaan 5. Namun apabila diperoleh lebih dari satu gejala, $\mathrm{CF}$ penyakit dihitung dengan persamaan 6 dalam perhitungan persentasi keyakinan.

Certainty factor mempunyai kelebihan yaitu sebagai berikut:

1. Yang mengandung ketidak pastian, metode ini sangat cocok digunakan dalam sistem pakar.

2. Keakuratan data dapat terjaga karena dalam sekali proses perhitungan hanya dapat mengolah 2 data saja.

Selain kelebihan, certainty juga memiliki

kekurangan yakni sebagai berikut:

1. Masih diperdebatkan pemodelan ketidak pastian yang menggunakan metode certainty factor

2. Harus dilakukan beberapa kali pengolahan data untuk data lebih dari 2 buah. 


\section{METODE PENELITIAN}

Dalam penelitian metode yang digunakan penulis adalah:

\section{Pengumpulan Data}

Pengumpulan data merupakan proses yang membantu peneliti dalam penelitian yang berfungsi untuk menyimpulkan hasil penelitian. Wawancara merupakan metode yang digunakan penulis dalam pengumpulan data yaitu penulis melakukan Tanya jawab melalui tatap muka dengan dokter spesialis dengan tujuan untuk mengetahui permasalahan yang ada di kilinik tersebut.

\section{Analisis Data}

Analisis data adalah yang dilakukan penulis untuk pengumpulan data dari hasil penelitian menjadi informasi yang nantinya bisa dipergunakan dalam mengambil kesimpulan. Data yang dianalisis penulis yakni gejala penyakit mata katarak dan jenis penyakit mata katarak.

3. Pengolahan Data

Pengolahan data merupakan yang bersifat teratur(sistematis) dan terencana dalam proses, cara, mengolah data untuk keperluan penelitian

4. perancangan

Tahap perencanaan ini merupakan tahapan yang merancang sebuah sistem pakar yang dapat digunakan user untuk mempermudah mengetahui jenis mata katarak serta gejala- gejala mata katarak. Aplikasi yang dibuat menggunakan bahasa pemograman PHP, agar lebih akurat hasilnya dengan metode certainty Factor.

\section{Implementasi}

Pada implementasi peneliti membahas yang diperoleh dari penelitian tentang kesimpulan dari hasil pengolahan data.

\section{HASIL DAN PEMBAHASAN}

Tabel 2 Gejala mata katarak
\begin{tabular}{|l|l|}
\hline Kode gejala & Nama gejala \\
\hline G01 & Penglihatan kabur \\
\hline G02 & Sensitif terhadap cahaya \\
\hline G03 & Pandangan berasap \\
\hline G04 & $\begin{array}{l}\text { Syeri padit melihat dimalam } \\
\text { hari }\end{array}$ \\
\hline G05 & $\begin{array}{l}\text { Ukuran lensa kaca mata } \\
\text { yang sering berubah }\end{array}$ \\
\hline G06 & Penglihatan ganda \\
\hline G07 & $\begin{array}{l}\text { Ada lingkaran putih } \\
\text { disekitar mata }\end{array}$ \\
\hline G08 & $\begin{array}{l}\text { Penglihatan warna } \\
\text { memudar atau tidak jelas }\end{array}$ \\
\hline G09 & \\
\hline
\end{tabular}

Pada tabel 2 menjelaskan kode gejala dan nama gejaladari penyakit mata katarak. Pada saat pengguna melakukan konsultasi gejala mata katarak digunakan untuk pertanyaan- pertanyaan yang akan keluar.
Tabel 3. Jenis mata katarak

\begin{tabular}{|l|l|}
\hline Kode jenis mata katarak & Nama penyakit \\
\hline P01 & Sekunder \\
\hline P02 & senilis \\
\hline P03 & komplikata \\
\hline P04 & Traumatika \\
\hline
\end{tabular}

Pada tabel 3 menjelaskan tentang kode jenis dan nama penyakit mata katarak. Tabel 3 digunakan sebagai hasil dari konsultasi yang sebelumnya menjawab pertanyaan - pertanyaan berupa gejala pada saat berkonsultasi. data jenis penyakit mata katarak diperoleh berdasarkan hasil wawancara dengan pakar.

Tabel 4. Bobot nilai gejala mata katarak

\begin{tabular}{|c|c|c|c|c|c|c|}
\hline Kode gejala & $\begin{array}{l}\text { Nama } \\
\text { gejala }\end{array}$ & $\begin{array}{l}\text { CF } \\
\text { P01 }\end{array}$ & $\begin{array}{l}\text { CF } \\
\text { P02 }\end{array}$ & $\begin{array}{c}\mathrm{CF} \\
\mathrm{P} 03\end{array}$ & $\begin{array}{l}\text { CF } \\
\text { P04 }\end{array}$ & $\begin{array}{l}\mathrm{CF} \\
\mathrm{P} 05\end{array}$ \\
\hline G01 & $\begin{array}{l}\text { Penglihatan } \\
\text { kabur }\end{array}$ & 0.8 & 0.2 & 0.6 & 0.4 & 1.0 \\
\hline G02 & $\begin{array}{l}\text { Sensitif } \\
\text { terhadap } \\
\text { cahaya }\end{array}$ & & 1.0 & 0.4 & & 0.6 \\
\hline G03 & $\begin{array}{l}\text { Pandangan } \\
\text { berasap }\end{array}$ & 0.6 & & 0.8 & & \\
\hline G04 & $\begin{array}{l}\text { Nyeri pada } \\
\text { mata }\end{array}$ & & & 0.2 & 1.0 & \\
\hline G05 & $\begin{array}{l}\text { Sulit } \\
\text { melihat } \\
\text { dimalam } \\
\text { hari } \\
\end{array}$ & & 0.2 & & & \\
\hline G06 & $\begin{array}{l}\text { Ukuran } \\
\text { lensa kaca } \\
\text { mata yang } \\
\text { sering } \\
\text { berubah } \\
\end{array}$ & & 0.6 & & & \\
\hline G07 & $\begin{array}{l}\text { Penglihatan } \\
\text { ganda }\end{array}$ & 0.2 & 0.6 & & 0.8 & 0.4 \\
\hline G08 & $\begin{array}{l}\text { Ada } \\
\text { lingakaran } \\
\text { putih } \\
\text { disekitar } \\
\text { mata }\end{array}$ & & 1.0 & & & \\
\hline G00 & $\begin{array}{l}\text { Penglihatan } \\
\text { warna } \\
\text { memudar } \\
\text { atau tidak } \\
\text { jelas }\end{array}$ & 0.4 & & & & 0.8 \\
\hline
\end{tabular}

Pada tabel 4 menjelaskan kode gejala, nama gejala, dan nilai $\mathrm{CF}$ setiap penyakit dan nilai CF setiap gejala pada penyakit katarak. Tabel 4 digunakan untuk proses perhitungan dalam menentukan nilai certainty factor . Tabel 5. Kaidah aturan/ rule

\begin{tabular}{|l|l|}
\hline No & \multicolumn{1}{|c|}{ Kaidah Aturan } \\
\hline 1 & $\begin{array}{l}\text { IF penglihatan kabur (G1) AND sensitive } \\
\text { terhadap cahaya (G2) AND penglihatan ganda } \\
\text { (G7) THEN penglihatan warna memudar atau } \\
\text { tidak jelas ( SEKUNDER) }\end{array}$ \\
\hline 2 & $\begin{array}{l}\text { IF penglihatan kabur(G1) AND sensitive } \\
\text { terhadap cahaya (G2) AND sulit melihat dimalam } \\
\text { hari (G5) AND penglihatan ganda (G7) AND ada } \\
\text { lingkaran putih disekitar mata (G8) THEN ( } \\
\text { SENILIS) }\end{array}$ \\
\hline 3 & $\begin{array}{l}\text { IF penglihatan kabur (G1) AND sensitive } \\
\text { terhadap cahaya (G2) AND pandangan } \\
\text { berasap(G3) THEN Nyeri pada mata } \\
\text { (KOMPLIKATA) }\end{array}$ \\
\hline 4 & $\begin{array}{l}\text { IF penglihatan kabur (G1) AND sensitive } \\
\text { terhadap cahaya (G2) AND penglihatan ganda ( }\end{array}$ \\
\hline
\end{tabular}


G7) THEN penglihatan warna memudar atau tidak jelas ( TRAUMATIKA)

Pada tabel $\mathbf{5}$ menjelaskan tentang aturan pada setiap penyakit dan gejala.Tabel 5 digunakan untuk penelusuran penyakit pada mata katarak berdasarkan setiap gejala yang di input.

Tabel 6. Bobot user
\begin{tabular}{|l|c|}
\hline \multicolumn{1}{|c|}{ Jawaban user } & Bobot \\
\hline Tidak tahu & 0.0 \\
\hline Tidak yakin & 0,2 \\
\hline kurang yakin & 0,4 \\
\hline Cukup yakin & 0,6 \\
\hline Yakin & 0,8 \\
\hline Sangat yakin & 1 \\
\hline
\end{tabular}

Pada tabel 6 menjelaskan jawaban user dan bobot dari jawaban yang dipilih user saat berkonsultasi. tabel 6 digunakan untuk sebagai jawaban user pada pakar saat berkonsultasi.

Tabel 7 Persentasi kesimpulan

\begin{tabular}{|l|l|l|}
\hline NO & $\begin{array}{l}\text { Tingkat } \\
\text { persentase }\end{array}$ & Nilai keyakinan \\
\hline 1 & $0 \%-60 \%$ & $\begin{array}{l}\text { Sedikit kemungkinan atau } \\
\text { kemungkinan kecil }\end{array}$ \\
\hline 2 & $\begin{array}{l}61 \%- \\
79 \%\end{array}$ & Kemungkinan besar \\
\hline 3 & $\begin{array}{l}80 \%- \\
99 \%\end{array}$ & Hampir pasti \\
\hline 4 & $100 \%$ & pasti \\
\hline
\end{tabular}

Pada tabel 7 menjelaskan tingkat persentase dan nilai keyakinan. Tabel 7 merupakan jumlah persentasi penyakit sehingga pengguna dapat mengetahui nilai keyakinan dan tingkat persentasi penyakit pada mata penyakit mata katarak.

Sebagai contoh perhitungan mendiagnosa penyakit mata katarak dengan metode certainty factor yaitu:

Untuk penyakit sekunder :

If Penglihatan kabur

And sensitive terhadap cahaya

And penglihatan ganda

Then penglihatan warna memudar atau tidak jelas

Langkah pertama yang harus dilakukan adalah pakar memberikan nilai CF setiap gejala.

Penglihatan kabur $=1.0$

Sensitive terhadap cahaya $=0.6$

Penglihatan ganda $=0.4$

Penglihatan warna memudar atau tidak jelas $=0.8$

Jawaban user :

Yakin $=0.8$

Tidak tahu $=0.2$

Cukup yakin $=0,6$

yakin $=0.8$

Kaidah - kaidah atau rule yang memiliki 4 premis (gejala), dipecah menjadi beberapa premis tunggal sebagai berikut:

Kaidah 1.1

If penglihatan kabur

Then sekunder

Kaidah 1.2

If sensitive terhadap cahaya
Then sekunder

Kaidah 1.3

If penglihatan ganda

Then sekunder

Kaidah 1.4

If penglihatan warna memudar atautidak jelas

Then sekunder

Langkah kedua :

Kaidah- kaidah atau rule yang baru tersebut kemudian dihitung nilai $\mathrm{CF}$ nya dengan mengalikan $\mathrm{CF}$ ( pakar) dengan CF ( user) menjadi:

Kaidah $1.1=1.0 * 0.8=0.8$

Kaidah $1.2=0,6^{*} 0.2=0.12$

Kaidah $1.3=0,4 * 0.6=0.24$

Kaidah $1.4=0.8 * 0.8=0.64$

Untuk penyakit selanjutnya karena lebih dari satu gejala digunakan persamaan 3.

$\mathrm{CF}$ combine1 $\left(\mathrm{CF}_{\text {gejala1, }} \mathrm{CF}_{\text {gejala2 }}\right)=\mathrm{CF}_{\text {gejala1 }}+\mathrm{CF}_{\text {gejala2 }}$ *(1- $\left.\mathrm{CF}_{\text {gejala } 1}\right)$

$$
\begin{aligned}
& =0.8+0.12 *(1-0.8) \\
& =0.8+0.12 *(0.2) \\
& =0.8+0.024
\end{aligned}
$$

$\mathrm{CF}$ old $1=0.824$

CFcombine2 $\left(\mathrm{CF}_{\text {0ld1 } 1} \mathrm{CF}_{\text {gejala } 3}\right)=\mathrm{CF}$ old $1+\mathrm{CF}_{\text {gejala } 3} *(1-$ $\left.\mathrm{CF}_{\text {old1 }}\right)$

$$
\begin{aligned}
& =0.824+0.24 *(1-0.824) \\
& =0.824+0.24 *(0.176) \\
& =0.824+0.042
\end{aligned}
$$

$\mathrm{CF}_{\text {old2 }}$

$$
=0.866
$$

CFcombine3 $\left(\mathrm{CF}_{\text {0ld2 } 2} \mathrm{CF}_{\text {gejala4 }}\right)=\mathrm{CF}_{\text {old } 2}+\mathrm{CF}_{\text {gejala } 4} *(1-$ $\mathrm{CF}_{\text {old2}}$ )

$$
\begin{aligned}
& =0.866+0.64 *(1-0.866) \\
& =0.866+0.64 *(0.134) \\
& =0.866+0.085
\end{aligned}
$$

$\mathrm{CF}_{\text {old } 3}$ $=0.951$

Maka kesimpulan: CF old terakhir CF penyakit, berdasarkan hasil perhitungan $\mathrm{CF}$ adalah sebagai berikut:

Persentase $=\mathrm{CF}_{\text {penyakit }} * 100$

$$
\begin{aligned}
& =0.951 * 100 \\
& =95 \%
\end{aligned}
$$

Terhadap senilis

Penglihatan kabur G01 (Kaidah 1) $=$ CF Pakar $*$ CF

$$
\text { User }=0.2 * 0.8=0.16
$$

Sensitif terhadap $\quad$ G02 (Kaidah 2) $=\mathrm{CF}$ Pakar $*$ CF cahaya $\quad$ User $=1 * 0.2=0.2$

Penglihatan ganda G07 (Kaidah 3) $=$ CF Pakar $*$ CF User $=0.6 * 0.6=0.36$

Terhadap Komplikata(P03)

Penglihatan kabur G01 (Kaidah 1) $=\mathrm{CF}$ Pakar $* \mathrm{CF}$ User $=0.6 * 0.8=0.48$

Sensitif terhadap $\quad$ G02 (Kaidah 2) $=$ CF Pakar $*$ CF cahaya $\quad$ User $=0.4 * 0.2=0.08$

Combain $1=0.48+(0.08 *(1-0.48)))=0.5216$

Terhadap Traumatika(P04)

Penglihatan G01 (Kaidah 1) $=$ CF Pakar * CF User

kabur $=0.4 * 0.8=0.32$

Penglihatan $\quad$ G07 (Kaidah 2) $=$ CF Pakar * CF User ganda $\quad=0.8 * 0.6=0.48$

Combain $1=0.32+(0.48 *(1-0.32)))=0.6464$ 
Dari perhitungan menggunakan metode certainty factor pada masing- masing penyakit, diperoleh nilai maximum $\mathrm{CF}$ adalah 0.951 atau $95 \%$ dengan penyakit sekunder (P01) .

Dari hasil perhitungan, berdasarkan tabel interpretasi dapat disimpulkan tingkat keyakinan adalah Hampir Pasti.

7. Implementasi sitem

Secara garis besar tampilan antar muka perancangan sitem pakar mendiagnosa penyakit mata katarak menggunakan metode certainty factor adalah

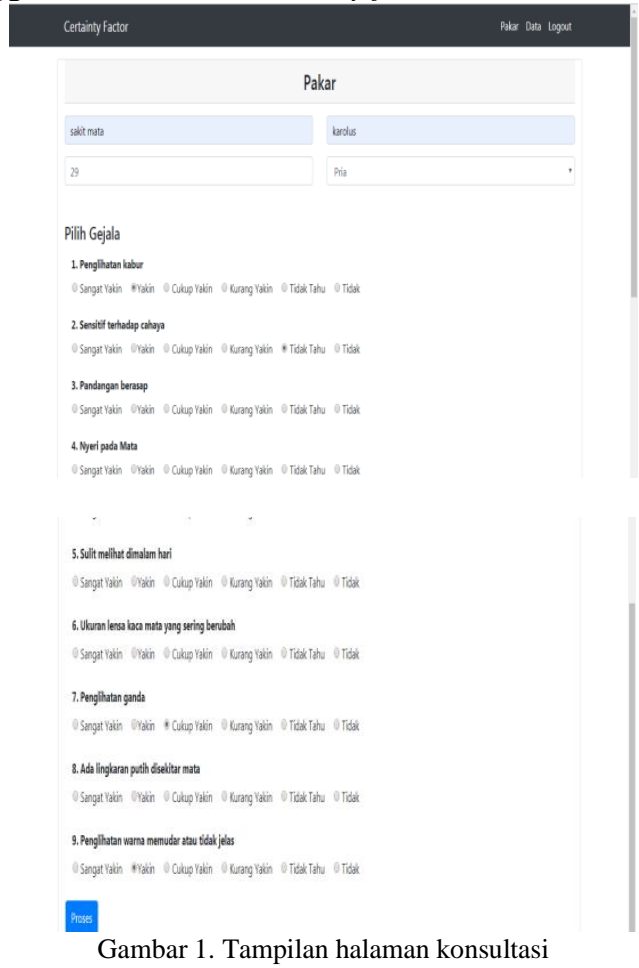

Pada gambar 1 Pada halaman konsultasi pasien diminta untuk mengisi judul diagnosa, nama pasien, , umur, dan jenis kelamin kemudian diproses. Dan jika pasien ingin ingin keluar dari halaman konsultasi maka pasien klik logout.

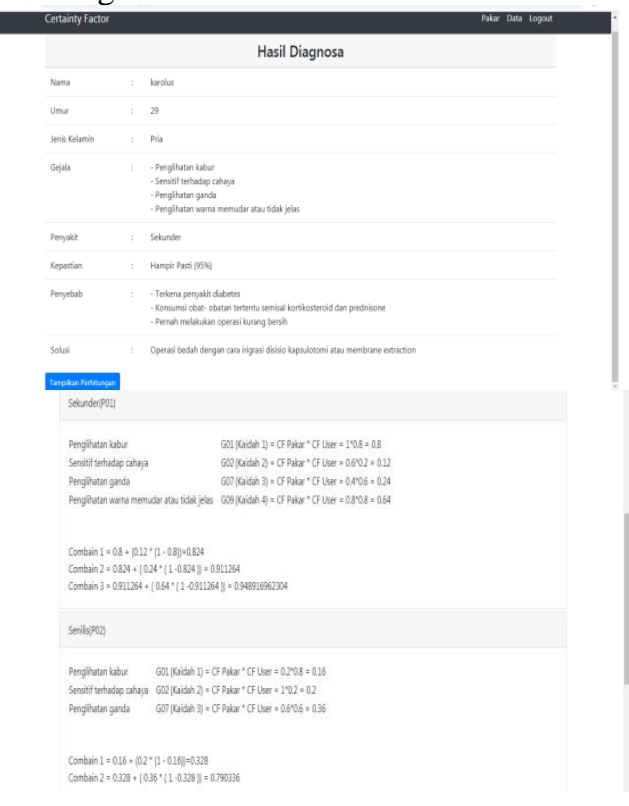

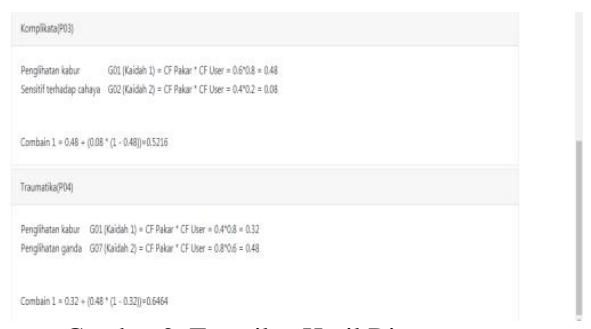

Gambar 2 Tampilan Hasil Diagnosa

Pada gambar 2 Pada form hasil diagnosa, akan ditampilkan nama pasien, umur, jenis kelamin,gejala, penyakit, kepastian, penyebab dan solusi. Untuk memastikan nilai kepastian dapat diklik tampilkan perhitungan.

\section{KESIMPULAN}

Dari hasil penelitian dengan membuat aplikasi sistem pakar untuk mendiagnosa penyakit mata katarak dengan metode certainty factor berbasis web menyimpulkan bahwa:

1. Dengan adanya sistem pakar mendiagnosa mata katarak dengan metode certainty factor dapat mempermudah pekerjaan pakar.

2. Dengan adanya sistem pakar certainty factor dapat mempermudah masyarakat untuk pencegahan lebih dini sebelum menderita penyakit katarak.

3. Sistem pakar ini menggunakan metode certainty factor dimana metode mengumpulkan pertanyaanpertanyaan serta solusi dari sistem tersebut dijawab sesuai dengan aturan rule yang dipakai dan data-data yang didapat selama penelitian.

\section{REFERENCES}

[1] Anik Andriani. 2016. Pemograman sistem pakar. Yogyakarta: Mediakom.

[2] Hariyanto, R., Basuki, A., \& Hasanah, R. N. 2016. Klasifikasi Penyakit Mata Katarak Berdasarkan Kelainan Patologis dengan Menggunakan Algoritma Learning Vector Quantization. Jurnal Network Engineering Research Operation [NERO] Vol. 2 No. 3.

[3] Jensen, B. A., Joseph, B., \& Lipták, B. G. 2005. Expert systems. In Instrument Engineers Handbook, Fourth Edition: Process Control and Optimization.

[4] Kharina eka setyaputri, Abdul Fadlil dan sunardi. 2018. Analisis Metode Certainty Factor Pada Sistem Pakar Diagnosa Penyakit THT. Jurnal Teknik Elektro Vol. 10 No. 1.

[5] Permana, Y., Wijaya, I. G. P. S., \& Bimantoro, F. 2017. Sistem Pakar Diagnosa Penyakit Mata Menggunakan Metode Certainty Factor Berbasis Science Android. Jurnal J-Cosine Vol. 1 No.1.

[6] T. Sutojoyo, Edy Muliyanto, dan Vinvent Suhartono. 2010. Kecerdasan Buatan. Andi Yogyakarta, Semarang.

[7] Virginia, G. 2010. Implementasi sistem pakar untuk mendiagnosis penyakit dengan gejala demam menggunakan metode certainty factor. Jurnal Informatika, Vol. 6 No. 1. 